\title{
Multidimensional fatigue in pulmonary hypertension: prevalence, severity and predictors
}

\author{
Todd M. Tartavoulle ${ }^{1}$, Aryn C. Karpinski ${ }^{2}$, Andrew Aubin ${ }^{3}$, Benzi M. Kluger ${ }^{4}$, \\ Oliver Distler ${ }^{5}$ and Lesley Ann Saketkoo 6,7,8
}

Affiliations: 'School of Nursing, Louisiana State University Health Sciences Center - New Orleans, New Orleans, LA, USA. ${ }^{2}$ Evaluation and Measurement, School of Foundations, Leadership and Administration, Kent State University, Kent, OH, USA. ${ }^{3}$ School of Medicine, Louisiana State University Health Sciences Center, New Orleans, LA, USA. "'Dept of Neurology, University of Colorado Anschutz Medical Campus, Aurora, CO, USA. ${ }^{5}$ Dept of Rheumatology, University Hospital Zurich, Zurich, Switzerland. ${ }^{6}$ New Orleans Scleroderma and Sarcoidosis Patient Care and Research Center, New Orleans, LA, USA. ${ }^{7}$ Tulane Lung Center, Tulane University School of Medicine, New Orleans, LA, USA. ${ }^{8}$ University Medical Center, Comprehensive Pulmonary Hypertension Center, University Medical Center, New Orleans, LA, USA.

Correspondence: Lesley Ann Saketkoo, Section of Pulmonary Medicine, 2nd Floor, J. Bennett Johnston Research Building, Tulane University School of Medicine, 1324 Tulane Avenue, New Orleans, LA 70112, USA. E-mail: LsaketkaTulane.edu

ABSTRACT Pulmonary hypertension is a potentially fatal disease. Despite pharmacological advances in pulmonary hypertension, fatigue remains common in patients with pulmonary hypertension.

A convenience sample of 120 participants at an international patient conference completed the Multidimensional Fatigue Inventory (MFI)-20 scale. Data on New York Heart Association Functional Class, body mass index, oxygen use and medication type/use were also collected.

There was a high prevalence of "severe" to "very severe" fatigue for each dimension: General Fatigue (60\%), Physical Fatigue (55.8\%), Reduced Activity (41.7\%), Reduced Motivation (32.5\%) and Mental Fatigue (27.5\%). The mean \pm SD overall MFI-20 score was 58 \pm 5.1 . Dimensions with the highest averaged levels were General Fatigue (13.40 \pm 3.61$)$, Physical Fatigue (13.23 \pm 3.67$)$ and Reduced Activity (11.33 \pm 4.16$)$. Body mass index correlated with higher fatigue scores. Phosphodiesterase inhibitor plus endothelin receptor antagonist combination negatively predicted General Fatigue, Physical Fatigue, Reduced Motivation and Reduced Activity. Triple therapy was a significant predictor of General Fatigue, Physical Fatigue and Reduced Activity. There were no significant predictors of Mental Fatigue.

Multidimensional fatigue is common and severe in patients with pulmonary hypertension. Phosphodiesterase inhibitor plus endothelin receptor antagonist combination resulted in lower scores in most fatigue dimensions. Comprehensive assessment of fatigue should be considered in the clinical care of patients with pulmonary hypertension and clinical research to develop formal interventions that target this disabling symptom.

@ERSpublications

Fatigue is common and severe in $\mathrm{PH}$, and impacted by medications; targeted strategies to mitigate fatigue are needed http://ow.ly/EISN30i0WWU

Cite this article as: Tartavoulle TM, Karpinski AC, Aubin A, et al. Multidimensional fatigue in pulmonary hypertension: prevalence, severity and predictors. ERJ Open Res 2018; 4: 00079-2017 [https://doi.org/10.1183/23120541.00079-2017].

Received: July 022017 | Accepted after revision: Jan 182018

Conflict of interest: None declared.

Support statement: This project was made possible by continued in-kind and financial support from the Pulmonary Hypertension Association, United Therapeutics Corporation support through the ISS program (Saketkoo ISS QOL-PH001) and Tulane University School of Medicine. This research was funded in part by grant T35HL105350 from the US National Heart, Lung, and Blood Institute. Funding information for this article has been deposited with the Crossref Funder Registry.

Copyright $\odot$ ERS 2018. This article is open access and distributed under the terms of the Creative Commons Attribution Non-Commercial Licence 4.0. 


\section{Introduction}

Pulmonary hypertension affects 12.4 per million people in the USA [1]. Aetiologies of pulmonary hypertension are diverse; however, dyspnoea is the most recognised symptom. Fatigue, defined as lack of energy or increased sense of effort with routine tasks, is a common, distinct symptom, but less clinically recognised [2, 3]. Clinically significant fatigue occurs in 57\% patients with pulmonary hypertension [2] and is reported as a primary disabling symptom as frequently as dyspnoea [4]. Little research has focused on patient experience, associative factors or impact of fatigue on function and health-related quality of life (HRQoL) in pulmonary hypertension [5].

Pulmonary hypertension-related functional impairment leads to difficulties maintaining/finding employment [2, 6, 7], potential hopelessness and anxiety stemming from fear of disease/symptom progression, and loss of social engagement [6-8]. Fatigue is generally associated with similar negative impact on HRQoL [9-13], suggesting a potential causative overlay in pulmonary hypertension HRQoL.

Despite pharmacological advances, fatigue remains an underrecognised and unaddressed symptom of pulmonary hypertension. Here, we examine: 1) prevalence and severity of fatigue as a multidimensional symptom, 2) differences in demographic characteristics and pulmonary hypertension severity indicators, and 3) pulmonary hypertension therapy associated with and predictive of fatigue.

\section{Methods}

Patients

Upon approval by the Pulmonary Hypertension Association (PHA) and the researchers' Institutional Review Board, data were collected onsite at the PHA 11th International Pulmonary Hypertension Conference and Scientific Sessions (Indianapolis, IN, USA) in 2014. All subjects registered with the PHA as both patients and research participants completed demographic questionnaires prior to enrolment allowing for patient queries to their physician.

Patients aged between 18 and 80 years with an established pulmonary hypertension diagnosis from any World Health Organization (WHO) group as self-reported on the PHA research form were included. Enquiry into literacy and communication vulnerabilities ascertained need for onsite assistance to complete the surveys.

\section{Multidimensional Fatigue Inventory}

Although not validated in pulmonary hypertension, the Multidimensional Fatigue Inventory (MFI)-20 was chosen as a sensitive instrument that could differentiate and examine, and thus provide an understanding of the severity and types of fatigue experienced in, people living with pulmonary hypertension. The MFI-20 precisely accommodates a cross-sectional examination of fatigue as a multidimensional phenomena, providing both total and dimensional subscale scores [14]. The MFI-20 is a patient-reported questionnaire developed in 1995, and is widely used in cancer and other chronic illnesses. It requires 5-10 min to complete and contains 20 items under five subscales (General Fatigue, Mental Fatigue, Physical Fatigue, Reduced Activity and Reduced Motivation), each with four items (two positively and two negatively worded items) rated on a 5-point Likert scale. Higher scores indicate higher fatigue levels. Dimension scores are categorised as mild (5-8), moderate (9-12), severe (13-16) and very severe (17-20). A total MFI score is used, but is less well validated and subject to underestimation of fatigue.

The MFI-20 is internally consistent and validated with Cronbach's $\alpha>0.80$ for the five subscales of fatigue [14], with good construct validity, good convergent and discriminant correlations with the visual analogue scale [14], and strong correlation with the Short Form-36 [15]. It has a minimal clinically important difference of 2 points in cancer-related investigations [16].

\section{Study variables and instruments}

Attestation of pulmonary hypertension diagnosis, WHO group (with subcategorisation, e.g. connective tissue disease), physician contact information, age, race, ethnicity, height, weight, oxygen use, New York Heart Association (NYHA) Functional Class [17], and pulmonary hypertension and nonpulmonary hypertension medication, dose and duration of use were collected. Month/year and age at diagnosis were collected on the PHA form, but not the initial onset of symptoms, leaving an ability to project disease duration.

\section{Procedure}

Unscheduled voluntary enlistment occurred in response to a PHA programme describing the project as "patient perspective of living with pulmonary hypertension" without indicating fatigue. Research sites were assigned by PHA and in an accessible location. After obtaining informed consent, MFI-20 was administered electronically via iPads with paper and verbal interview options available. 


\section{Statistical analysis}

An $a$ priori power analysis for multiple regression using $\mathrm{G}^{\star}$ Power 3 (www.gpower.hhu.de) (power=0.80, $\alpha=0.05$ ) yielded a minimum sample size of 98 to detect a medium effect.

SPSS version 22.0 (IBM, Armonk, NY, USA) was used to analyse basic descriptive statistics. Skewness and kurtosis statistics were examined, with all data approximating a normal distribution. Depending on variable type, appropriate statistical analyses examined relationships (i.e. Pearson correlations, independent t-tests or ANOVAs). Prior to hierarchical regression analyses, bivariate correlations examined all predictors and outcome variables (i.e. fatigue dimensions). Point biserial ( $\mathrm{rpb}$ ) correlations were applied to dichotomous and continuous variables. Controlling for type I error (impact of multiple comparisons), the Bonferroni correction was applied $(\alpha=0.05 / 5=0.01)$.

\section{Results}

\section{Participants}

The entire cohort of 120 participants (300 total PHA attendees) completed all items and were WHO group I $(55.8 \%(n=67)$ idiopathic, $13.3 \%(n=16)$ connective tissue disease related), with a mean \pm SD age of $52.61 \pm 14.0$ years (range $21-79$ years); $88.3 \%(n=106)$ were female and $85.8 \%(n=103)$ were White, with $48.3 \%(\mathrm{n}=58)$ classifiable as "obese" $\left(\mathrm{BMI} \geqslant 30 \mathrm{~kg} \cdot \mathrm{m}^{-2}\right)($ table 1$)$.

The largest proportions were NYHA Functional Class II $(\mathrm{n}=70(58.3 \%))$ and III $(\mathrm{n}=35(29.2 \%))$, with $52.5 \%$ ( $n=63$ ) requiring supplemental oxygen.

\section{Medications}

Prostacyclin (prostaglandin $\mathrm{I}_{2}\left(\mathrm{PGI}_{2}\right)$ ), phosphodiesterase inhibitor (PDEI) and endothelin receptor antagonist (ERA) use occurred in 63 (52.5\%), $83(69.2 \%)$ and 59 (49.2\%) of participants, respectively. 32 (26.7\%) participants were on single, $52(43.3 \%)$ on dual and $23(19.2 \%)$ on triple combination therapy. For dual therapy, PDEI+PGI 2 was used in $25(20.8 \%)$, PDEI+ERA in 20 (16.7\%) and $\mathrm{PGI}_{2}+\mathrm{ERA}$ in seven (5.8\%) participants.

\section{MFI psychometric and descriptive information}

Reduced Activity and Mental Fatigue subscales had the highest internal consistency $(\alpha=0.775$ and 0.798 , respectively). The General Fatigue, Reduced Motivation and Physical Fatigue dimensions were slightly lower $(\alpha=0.651,0.687$ and 0.679 , respectively). Skewed distribution was examined for each dimension with additional assessment for $>15 \%$ of respondents achieving the highest level indicating a ceiling effect. For all subscales, no ceiling effects were present.

\section{Prevalence and severity of fatigue in pulmonary hypertension}

The mean \pm SD total score was $58 \pm 5.1$. Of participants scoring "severe"/"very severe" (figure 1), General Fatigue $(13.40 \pm 3.61, \mathrm{n}=72(60.0 \%))$ and Physical Fatigue $(13.23 \pm 3.67, \mathrm{n}=67(55.8 \%))$ had higher mean scores than other subscales $(\mathrm{F}=34.612$, d.f. $=4,116 ; \mathrm{p}<0.0001)$, followed by Reduced Activity $(11.33 \pm 4.16, \mathrm{n}=50(41.7 \%))$, Mental Fatigue $(10.42 \pm 3.98, \mathrm{n}=39(32.5 \%))$ and Reduced Motivation $(10.30 \pm 3.59 ; \mathrm{n}=33(27.5 \%))$.

\section{Patient characteristics and fatigue}

Neither the MFI-20 dimensions nor total scores demonstrated significant differences in age, sex and race (table 2).

No significant differences occurred between the "idiopathic" and other groups, including between the connective tissue disease group ( $\mathrm{p}>0.05$ on all dimensions and total score).

BMI was dichotomised into "obese" $\left(\geqslant 30 \mathrm{~kg} \cdot \mathrm{m}^{-2}\right)$ and "less than obese" $\left(\leqslant 29.9 \mathrm{~kg} \cdot \mathrm{m}^{-2}\right)$, combining "overweight", "healthy" and "underweight". Mean \pm SD total scores were higher for "obese" $(64.41 \pm 15.24$; $\mathrm{p}<0.001)$ than "less than obese" $(53.34 \pm 13.08)$, and in three dimensions: Reduced Activity $(\mathrm{p}<0.001)$, Physical Fatigue $(\mathrm{p}=0.002)$, with the largest differences in Mental Fatigue $(12.34 \pm 3.84$ versus $8.63 \pm 3.21$; $\mathrm{p}<0.001)$.

\section{Pulmonary hypertension severity indicators}

Compared with NYHA Functional Class I/II, Functional Class III/IV had higher mean \pm SD total MFI-20 $(67.26 \pm 11.61$ versus $54.57 \pm 14.99 ; \mathrm{p}<0.001)$ and in four dimensions: Reduced Activity $(13.74 \pm 3.31$ versus $10.17 \pm 4.05 ; \mathrm{p}<0.0001)$, Reduced Motivation (12.49 \pm 3.22 versus 9.25 $\pm 3.28 ; \mathrm{p}<0.0001$ ), Physical Fatigue $(14.54 \pm 2.63$ versus $12.60 \pm 3.94 ; \mathrm{p}=0.002)$ and Mental Fatigue $(12.64 \pm 3.89$ versus $9.36 \pm 3.58 ; \mathrm{p}<0.0001)$.

Patients using supplemental oxygen demonstrated higher mean \pm sD total scores $(62.62 \pm 13.27$ versus 54.35 $\pm 16.03 ; \mathrm{p}=0.003)$ and in all five dimensions: Reduced Activity ( $\mathrm{p}=0.034)$, Reduced Motivation 


\begin{tabular}{|c|c|}
\hline Subjects & 120 \\
\hline Age years & $52.61 \pm 14.0$ \\
\hline \multicolumn{2}{|l|}{ Sex } \\
\hline Male & 14 (11.7) \\
\hline Female & 106 (88.3) \\
\hline \multicolumn{2}{|l|}{ Race } \\
\hline White & 103 (85.8) \\
\hline Other & $17(14.2)$ \\
\hline African-American/Black & $7(5.8)$ \\
\hline Hispanic or Latino & $6(5.0)$ \\
\hline Asian & $2(1.7)$ \\
\hline Native American & $2(1.7)$ \\
\hline \multicolumn{2}{|l|}{ BMI } \\
\hline Less than obese & 62 (51.7) \\
\hline Underweight (BMI $<18.5 \mathrm{~kg} \cdot \mathrm{m}^{-2}$ ) & $2(1.7)$ \\
\hline Healthy weight (BMI $18.5-24.9 \mathrm{~kg} \cdot \mathrm{m}^{-2}$ ) & $27(22.5)$ \\
\hline Overweight (BMI $25.0-29.9 \mathrm{~kg} \cdot \mathrm{m}^{-2}$ ) & 33 (27.5) \\
\hline Obese $\left(\mathrm{BMI} \geqslant 30 \mathrm{~kg} \cdot \mathrm{m}^{-2}\right)$ & $58(48.3)$ \\
\hline \multicolumn{2}{|l|}{ WHO group I breakdown } \\
\hline Idiopathic & $67(55.8)$ \\
\hline Other & $53(44.2)$ \\
\hline Connective tissue disease & $16(13.3)$ \\
\hline Unknown & $13(10.8)$ \\
\hline Congenital heart disease & $7(5.8)$ \\
\hline Drug/toxin induced & $4(3.3)$ \\
\hline Heritable & $3(2.5)$ \\
\hline Idiopathic with heritable & $3(2.5)$ \\
\hline Other & $7(5.7)$ \\
\hline \multicolumn{2}{|l|}{ NYHA Functional Class } \\
\hline I/II & 81 (67.5) \\
\hline I & $11(9.2)$ \\
\hline$\|$ & 70 (58.3) \\
\hline III/IV & 39 (32.5) \\
\hline III & $35(29.2)$ \\
\hline IV & 4 (3.3) \\
\hline Oxygen use & 63 (52.5) \\
\hline \multicolumn{2}{|l|}{ Medications } \\
\hline $\mathrm{PGI}_{2}$ & $8(6.6)$ \\
\hline PDEI & 15 (12.5) \\
\hline ERA & 9 (7.5) \\
\hline $\mathrm{PGI}_{2}+\mathrm{PDEI}$ & $25(20.8)$ \\
\hline $\mathrm{PGI}_{2}+\mathrm{ERA}$ & $7(5.8)$ \\
\hline PDEI+ERA & $20(16.7)$ \\
\hline $\mathrm{PGI}_{2}+\mathrm{PDEI}+\mathrm{ERA}$ & $23(19.2)$ \\
\hline
\end{tabular}

Data are presented as $\mathrm{n}$, mean \pm SD or $\mathrm{n}(\%)$. BMI: body mass index; WHO: World Health Organization; NYHA: New York Heart Association; $\mathrm{PGI}_{2}$ : prostaglandin $\mathrm{I}_{2}$; PDEI: phosphodiesterase inhibitor; ERA: endothelin receptor antagonist.

( $\mathrm{p}=0.036)$, General Fatigue $(\mathrm{p}=0.003)$, Physical Fatigue $(\mathrm{p}=0.042)$, with the largest differences in Mental Fatigue scores $(11.37 \pm 3.74$ versus $9.39 \pm 3.99 ; \mathrm{p}=0.006)$.

\section{Pulmonary hypertension medications}

Pulmonary hypertension medication associations with fatigue

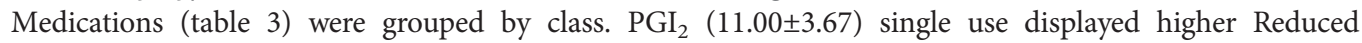
Motivation (9.60 $\pm 3.39 ; \mathrm{p}=0.032)$ than PDEI or ERA single use.

Regarding dual therapy, $\mathrm{PGI}_{2}+\mathrm{PDEI}$ had higher total $(62.68 \pm 14.24 ; \mathrm{p}=0.020)$, Reduced Motivation $(11.32 \pm 3.62 ; \mathrm{p}=0.012)$ and General Fatigue $(14.49 \pm 3.59 ; \mathrm{p}=0.007)$ scores. $\mathrm{PGI}_{2}+\mathrm{ERA}$ use had higher total (63.92 $\pm 13.67 ; \mathrm{p}=0.046)$ and General Fatigue (14.92 $\pm 3.48 ; \mathrm{p}=0.015)$ scores. $\mathrm{PGI}_{2}+\mathrm{PDEI}+\mathrm{ERA}$ demonstrated higher Reduced Motivation (11.90 $\pm 4.06 ; p=0.023)$, General Fatigue (15.57 $\pm 3.20 ; p=0.002)$ and Mental Fatigue (12.05 $\pm 4.60 ; \mathrm{p}=0.039)$ scores. 


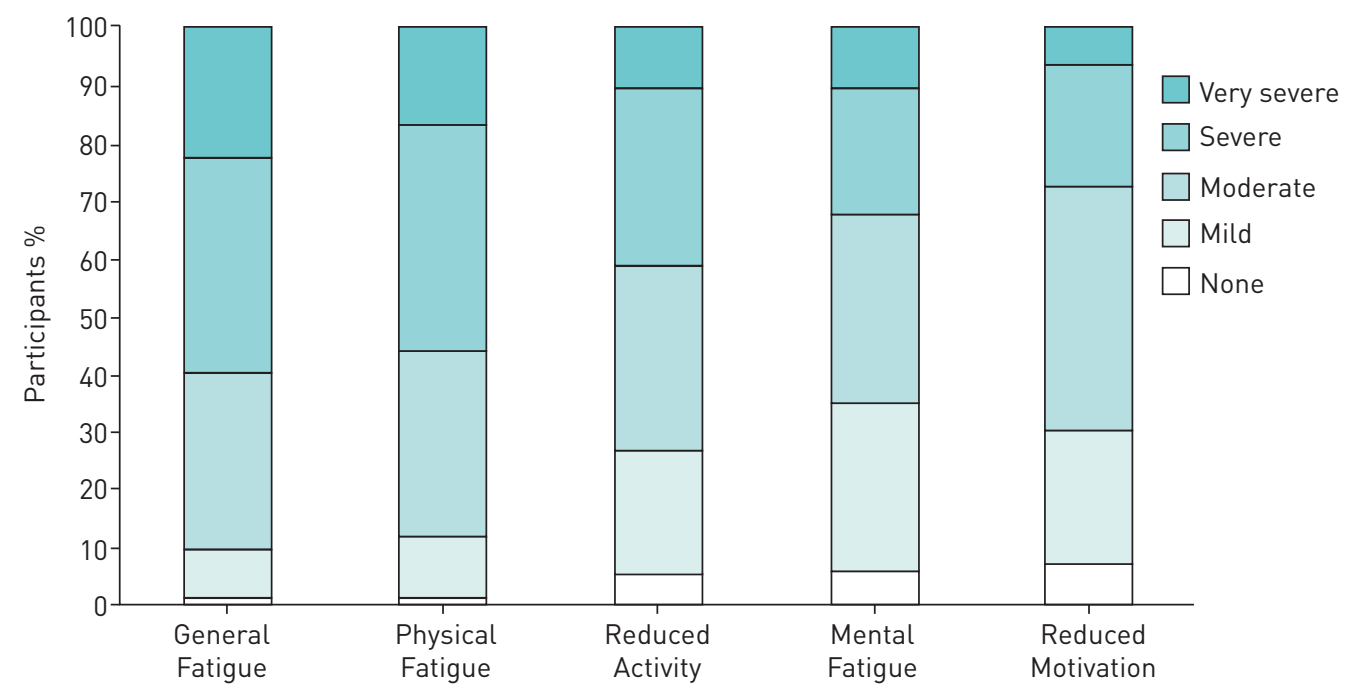

FIGURE 1 Distribution of fatigue severity among the Multidimensional Fatigue Inventory-20 fatigue dimensions.

Medication predictors of fatigue in pulmonary hypertension

Hierarchical multiple regression analyses supported positive relationships found between $\mathrm{PGI}_{2}(\mathrm{rpb}=0.201$, $\mathrm{p}=0.027), \quad \mathrm{PGI}_{2}+\mathrm{PDEI}(\mathrm{rpb}=0.240, \mathrm{p}=0.008)$ and triple therapy $(\mathrm{rpb}=0.196, \mathrm{p}=0.032)$ with Reduced Motivation, as well as between $\mathrm{PGI}_{2}(\mathrm{rpb}=0.197, \mathrm{p}=0.031), \mathrm{PGI}_{2}+\mathrm{ERA}(\mathrm{rpb}=0.263, \mathrm{p}=0.004), \mathrm{PGI}_{2}+\mathrm{PDEI}$ $(\mathrm{r} p \mathrm{~b}=0.257, \mathrm{p}=0.005)$ and triple therapy $(\mathrm{r} \mathrm{pb}=0.311, \mathrm{p}=0.001)$ with General Fatigue.

\section{TABLE 2 Fatigue dimension and patient ${ }^{\#}$ characteristics}

\begin{tabular}{|c|c|c|c|c|c|c|c|}
\hline & Patients & $\begin{array}{c}\text { Reduced } \\
\text { Activity }\end{array}$ & $\begin{array}{l}\text { Reduced } \\
\text { Motivation }\end{array}$ & $\begin{array}{l}\text { General } \\
\text { Fatigue }\end{array}$ & $\begin{array}{l}\text { Physical } \\
\text { Fatigue }\end{array}$ & $\begin{array}{l}\text { Mental } \\
\text { Fatigue }\end{array}$ & Total \\
\hline \multicolumn{8}{|l|}{ Sex } \\
\hline Female & 106 & $\begin{array}{c}11.35 \pm 4.31 \\
(4-20)\end{array}$ & $\begin{array}{c}10.40 \pm 3.67 \\
(4-20)\end{array}$ & $\begin{array}{c}13.53 \pm 3.67 \\
(4-20)\end{array}$ & $\begin{array}{c}13.29 \pm 3.77 \\
(4-20)\end{array}$ & $\begin{array}{c}10.43 \pm 4.06 \\
(4-20)\end{array}$ & $\begin{array}{c}59.00 \pm 15.16 \\
(26-92)\end{array}$ \\
\hline \multicolumn{8}{|l|}{ Race } \\
\hline Other & 17 & $\begin{array}{c}10.59 \pm 4.23 \\
(4-17)\end{array}$ & $\begin{array}{c}9.00 \pm 3.61 \\
(4-18)\end{array}$ & $\begin{array}{c}12.47 \pm 3.91 \\
(4-19)\end{array}$ & $\begin{array}{c}12.47 \pm 3.73 \\
(6-20)\end{array}$ & $\begin{array}{c}10.47 \pm 4.57 \\
(4-19)\end{array}$ & $\begin{array}{c}55.00 \pm 17.50 \\
(26-87)\end{array}$ \\
\hline \multicolumn{8}{|l|}{ BMI } \\
\hline Less than obese & 62 & $\begin{array}{c}9.85 \pm 3.79 \\
(4-20)\end{array}$ & $\begin{array}{c}9.52 \pm 3.42 \\
(4-20)\end{array}$ & $\begin{array}{c}13.11 \pm 3.27 \\
(6-20)\end{array}$ & $\begin{array}{c}12.23 \pm 3.72 \\
(4-19)\end{array}$ & $\begin{array}{c}8.63 \pm 3.21 \\
(4-18)\end{array}$ & $\begin{array}{c}53.34 \pm 13.08 \\
(26-78)\end{array}$ \\
\hline Other & 53 & $\begin{array}{c}11.40 \pm 3.98 \\
(4-20)\end{array}$ & $\begin{array}{c}10.21 \pm 3.24 \\
(4-19)\end{array}$ & $\begin{array}{c}13.40 \pm 3.66 \\
(4-20)\end{array}$ & $\begin{array}{c}12.79 \pm 3.09 \\
(6-20)\end{array}$ & $\begin{array}{c}10.28 \pm 3.72 \\
(4-19)\end{array}$ & $\begin{array}{c}58.08 \pm 14.03 \\
(26-92)\end{array}$ \\
\hline \multicolumn{8}{|c|}{ NYHA Functional Class } \\
\hline I/II & 81 & $\begin{array}{c}10.17 \pm 4.05 \\
(4-20)\end{array}$ & $\begin{array}{c}9.25 \pm 3.28 \\
(4-20)\end{array}$ & $\begin{array}{c}13.19 \pm 3.89 \\
(4-20)\end{array}$ & $\begin{array}{c}12.60 \pm 3.94 \\
(4-20)\end{array}$ & $\begin{array}{c}9.36 \pm 3.58 \\
(4-20)\end{array}$ & $\begin{array}{c}54.57 \pm 14.99 \\
(26-91)\end{array}$ \\
\hline III/IV & 39 & $\begin{array}{c}13.74^{* * *} \pm 3.31 \\
(6-20)\end{array}$ & $\begin{array}{c}12.49 * * * \pm 3.22 \\
(6-19)\end{array}$ & $\begin{array}{c}13.85 \pm 2.95 \\
(8-20)\end{array}$ & $\begin{array}{c}14.54^{* *} \pm 2.63 \\
(10-20)\end{array}$ & $\begin{array}{c}12.64^{* * *} \pm 3.89 \\
(5-20)\end{array}$ & $\begin{array}{c}67.26^{* * *} \pm 11.61 \\
(43-92)\end{array}$ \\
\hline Oxygen use & 63 & $\begin{array}{c}12.10 * \pm 4.17 \\
(4-20)\end{array}$ & $\begin{array}{c}10.95^{*} \pm 3.44 \\
(4-20)\end{array}$ & $\begin{array}{c}14.32^{* *} \pm 3.11 \\
(6-20)\end{array}$ & $\begin{array}{c}13.89 * \pm 3.13 \\
(6-20)\end{array}$ & $\begin{array}{c}11.37^{* *} \pm 3.74 \\
(4-20)\end{array}$ & $\begin{array}{c}62.62^{* *} \pm 13.27 \\
(27-92)\end{array}$ \\
\hline \multicolumn{8}{|c|}{$\begin{array}{l}\text { Data are presented as } n \text { or mean } \pm S D \text { (minimum-maximum). BMI: body mass index; PAH: pulmonary arterial hypertension; NYHA: New York } \\
\text { Heart Association. For oxygen use, only "Yes" descriptive statistics are reported. " } n=120 \text { patients. }{ }^{*}: p<0.05 ;{ }^{* *}: p<0.01 ;{ }^{* * *}: p<0.001 \text {. } \\
\text { Asterisks follow the higher mean for the fatigue dimension. }\end{array}$} \\
\hline
\end{tabular}


TABLE 3 Fatigue dimension scores and medication use

$\begin{array}{cccc}\text { General Fatigue } & \text { Physical Fatigue } & \text { Mental Fatigue } & \text { Total } \\ 14.00 \pm 3.71 & 13.65 \pm 3.57 & 11.03 \pm 4.33 & 61.10 \pm 14.54 \\ (5-20) & (4-20) & (4-20) & (28-91) \\ 13.77 \pm 3.39 & 13.43 \pm 3.51 & 10.57 \pm 4.03 & 59.90 \pm 14.51 \\ (5-20) & (4-20) & (4-20) & (27-92) \\ 13.73 \pm 3.66 & 12.88 \pm 4.00 & 10.17 \pm 4.14 & 58.52 \pm 15.98 \\ (5-20) & (5-20) & (4-19) & (26-87) \\ 14.49 * * \pm 3.59 & 13.81 \pm 3.57 & 11.28 \pm 4.48 & 62.68^{*} \pm 14.24 \\ (5-20) & (4-20) & (4-20) & (28-91) \\ 14.92^{*} \pm 3.48 & 13.46 \pm 3.73 & 11.85 \pm 4.54 & 63.92^{*} \pm 13.67 \\ (5-20) & (5-20) & (4-19) & (33-87) \\ 13.92 \pm 3.46 & 12.81 \pm 3.64 & 10.53 \pm 4.40 & 58.69 \pm 15.55 \\ (5-20) & (6-20) & (4-19) & (27-87) \\ 15.57 * * \pm 3.20 & 14.00 \pm 3.52 & 12.05 * \pm 4.60 & 66.24^{*} \pm 12.78 \\ (5-20) & (7-20) & (4-19) & (34-87)\end{array}$

Data are presented as $\mathrm{n}$ or mean $\pm \mathrm{SD}$ (minimum-maximum). $\mathrm{PGI}_{2}$ : prostaglandin $\mathrm{I}_{2}$; PDEI: phosphodiesterase inhibitor; ERA: endothelin receptor antagonist. Only "Yes" descriptive statistics are reported. *: $p<0.05 ;{ }^{* *}: p<0.01$. Asterisks follow the higher mean for the fatigue dimension.

Triple therapy $(\mathrm{p}<0.05)$ predicted General Fatigue, while PDEI+ERA $(\mathrm{p}<0.05)$ predicted reduced General Fatigue.

PDEI use alone $(\mathrm{p}<0.05)$ and triple therapy $(\mathrm{p}<0.01)$ were significant predictors of Physical Fatigue, while $\mathrm{PGI}_{2}+\mathrm{ERA}(\mathrm{p}<0.05)$ and PDEI+ERA $(\mathrm{p}<0.01)$ predicted reduced Physical Fatigue.

For Mental Fatigue, no significant medication regimen predictors were identified.

PDEI+ERA $(\mathrm{p}<0.05)$ predicted lower fatigue scores in Reduced Motivation.

PDEI $(\mathrm{p}<0.01)$ single use, ERA single use $(\mathrm{p}<0.01)$ and triple therapy $(\mathrm{p}<0.01)$ predicted Reduced Motivation, while PDEI+ERA $(\mathrm{p}<0.001)$ predicted low scores in Reduced Activity.

\section{Discussion}

This is the first investigation to characterise multidimensional aspects of fatigue in group I pulmonary hypertension demonstrating a severity prevalence comparable to that of cancer [18] and higher than rheumatoid arthritis [19], and calls for further investigation into pulmonary hypertension-related fatigue. The identification and management of fatigue in pulmonary hypertension has been outside the purview of current pulmonary hypertension treatment strategies. Despite participants possessing health and self-efficacy sufficient for conference attendance, fatigue severity was high. Regardless, fatigue remains an underrecognised clinical and research concern, and is likely influenced by the total pulmonary hypertension experience of disease process, medication/management and psychosocial effects.

The MFI-20 has face validity and demonstrated feasibility in both time and scoring, but has not yet been validated for use in pulmonary hypertension. The MFI-20, broadly validated in other diseases, provides a granular assessment into the types of fatigue that contribute to a patient's pulmonary hypertension experience, providing an opportunity for clinical recognition, anticipatory education and prescription strategies such as supervised physical training to enhance/protect peripheral muscle strength and reserve. Further results indicate higher scores in General Fatigue and dimensions of physical function, i.e. Physical Fatigue and Reduced Activity.

Neither age, sex or race had significant association on fatigue severity in any dimension. Not surprisingly, differences in total fatigue and dimensions were with higher NYHA classification and oxygen use. Oxygen use was associated with higher scores in all dimensions. In addition to the systemic effects of hypoxia, daily logistical burdens of management with the cumbersome weight and organisation of equipment may impact dimensional fatigue.

Appearing contradictory, NYHA Functional Class III/IV was related to higher scores in the total and all subscales except General Fatigue; however, the total averaged score was still very high as was NYHA Functional Class I/II (though statistically lower). Given our negative investigations into a ceiling effect, this 
may speak to a yet unrecognised aspect of fatigue specific to pulmonary hypertension captured within the other dimensions which might be elucidated through qualitative mixed methods studies.

Several interesting findings regarding medication emerged when controlling for severity indicators, most notably the predictive impact of PDEI+ERA with lower fatigue scores in all dimensions except for Mental Fatigue, which is encouraging given recent regulatory approval of this specific combined therapy [20]. However, addition of $\mathrm{PGI}_{2}$, when controlling for NYHA Functional Class and oxygen use, was strongly predictive of higher General Fatigue, Physical Fatigue and Reduced Activity scores by $>6$ points, while 2 points is the accepted minimal clinically important difference [15]. These findings at face value make sense. Targeting pulmonary arterial hypertension at two different vasoconstrictive pathways using medications that are most tolerable in pulmonary arterial hypertension (PDEI and ERA) improves the vasodilatory response without escalating the patient burden of side-effects. However, prostacyclins $\left(\mathrm{PGI}_{2}\right)$ have a high side-effect profile and are logistically burdensome in terms of administration and self-management. An equally reasonable consideration is that patients on $\mathrm{PGI}_{2}$ and in any combination may be perceived to have more severe disease, and thus higher fatigue scores.

Elevated BMI was associated with higher scores in all but General Fatigue. Whether weight management favourably impacts pulmonary hypertension fatigue is yet to be investigated. Safe exercise and nutrition, however, are healthful activities that may provide targeted improvement in deconditioning-related pulmonary hypertension fatigue.

Mental Fatigue was predominantly mild to moderate without significant beneficial or pejorative impact by pulmonary hypertension medications. However, this dimension was severe/very severe for $35 \%$ of participants and found to be higher with oxygen use, NYHA Functional Class III/IV and triple therapy. These findings likely speak to strata of disease severity, and require investigation into self-management and clinician-directed strategies to preserve perceived brain function and thus potentially HRQoL.

Complete alleviation of pulmonary hypertension fatigue may not be a realistic goal; however, strategies to minimise the distress of fatigue severity are a worthy effort, as has been shown in multiple sclerosis, cancer and other disease processes [21-27]. Pharmaceutical interventions such as methylphenidate may have an overall pejorative impact on pulmonary hypertension health outcomes, with others such as modafinil being unknown in patients with vascular disease. Large cohorts demonstrated efficacy without discernible toxicity of American ginseng in cancer-related fatigue [27]. Nonpharmacological interventions have been successfully utilised to reduce cancer-related fatigue, such as mindfulness meditation, yoga and tai chi, as well as dance and other exercise [21, 22, 24, 26, 27].

This study has several limitations. Although use of the MFI-20 makes sense hypothetically and demonstrated internal consistency in this study, it is not fully validated in pulmonary hypertension. The study's cross-sectional nature is unable to assess instrument discrimination of fatigue changes over time and thus unable to contribute to validation of the MFI-20 for specific use in pulmonary hypertension. Comparative studies with other fatigue instruments, such as PROMIS [28], would be important before using the MFI-20 as a secondary outcome measure in pulmonary hypertension clinical trials. Participants attending the PHA conference may not be representative of the overall pulmonary hypertension population, raising questions of selection bias as well as lack of a control group. Furthermore, risk status for untreated obstructive sleep apnoea was not assessed, which would be an important confounding variable for fatigue severity especially in patients with elevated BMI. Nevertheless, results from this study provide direction in identifying dimensions of fatigue as experienced in pulmonary hypertension, a complex disease involving a symptom, dyspnoea, which in itself is physically exhausting, with downstream fatigue-associated sequelae of oxygen deprivation on cognition, systemic vasculature, and muscle and nerve health. This study demonstrates severity levels similar to those in rheumatological and oncological conditions [18, 19], and provides guidance on identifying patients at risk for fatigue type, potential enhancements to consider in relation to predictors of fatigue and investigations in total patient-centred care in pulmonary hypertension that targets strategies by fatigue type.

Furthermore, much of the data is collected by PHA without medical record validation, and lacking potentially influential information such as disease duration and haemodynamics. This is primarily concerning WHO group designation, which is the only third-party communication (doctor to patient), whereas all other data is first-party reported (known intrinsically by the patient). This limitation might be more serious if our WHO group proportion conflicted with the distribution of past PHA conference attendances, which is predominantly group I and very few other groups in attendance. Although no significant differences in fatigue were found between the idiopathic and connective tissue disease groups, sample size differences were large, possibly influencing the analysis. 
Tandem assessment of standard HRQoL, depression, sleep quality or dyspnoea questionnaires was not attempted for correlative analysis $[5,29]$ with reasoning that conference attendance is frenetic and exhausting, albeit an exciting experience for patients. Prolonged participation time might have interfered with either research involvement or attendance at important educational sessions. For this reason, it was pre-determined to reserve introduction of correlative instruments for future nonconference cohorts.

In rheumatoid arthritis, symptom-querying focus groups identified fatigue as important to patients and subsequently validated it for inclusion as a reliable, discriminatory measure for clinical trial use [30]. It is yet unknown which currently available fatigue scale provides the most accurate and discriminatory reflection of pulmonary hypertension fatigue, but continued qualitative investigations will identify content and language relevant to people living with pulmonary hypertension, and further define the relevance of MFI-20 and other fatigue instruments, potentially revealing a need for a pulmonary hypertension-specific fatigue or HRQoL instrument. The Cambridge Pulmonary Hypertension Outcome Review [31] may have been one such instrument, but its costliness prohibits use in clinical settings and nonpharmaceutical research, and thus it remains unavailable to most patient-centred and patient care efforts in pulmonary hypertension.

Examination of longitudinal correlates with pulmonary hypertension fatigue such as haemodynamic coordinates, disease duration, mental health, HRQoL, illness behaviour and symptom interference is needed [32]. Pilot investigations of nonpharmacological therapies targeting pulmonary hypertension-specific fatigue are warranted. The authors currently recommend use of the MFI-20 with concurrent use of the fatigue visual analogue scale and at least one additional fatigue instrument until a fully validated instrument in pulmonary hypertension is identified.

\section{Conclusions}

Significant fatigue severity was detected in group I pulmonary hypertension, particularly in General Fatigue, Physical Fatigue and Reduced Activity, potentially indicating priority areas of targeted intervention. BMI was associated with higher scores, prompting consideration of weight management for symptom amelioration. PDEI+ERA therapy predicted favourable impact on fatigue dimensions, while addition of $\mathrm{PGI}_{2}$ predicted worse fatigue scores. Continued investigations into fatigue assessment may provide important data regarding the utility of fatigue as a discriminatory measure in pulmonary hypertension and, very importantly, development of targeted interventions to alleviate and/or manage fatigue.

\section{References}

1 Frost AE, Badesch DB, Barst RJ, et al. The changing picture of patients with pulmonary arterial hypertension in the United States: how REVEAL differs from historic and non-US contemporary registries. Chest 2011; 139: 128-137.

2 Swetz KM, Shanafelt TD, Drozdowicz LB, et al. Symptom burden, quality of life, and attitudes toward palliative care in patients with pulmonary arterial hypertension: results from a cross-sectional patient survey. J Heart Lung Transplant 2012; 31: 1102-1108.

3 Kluger BM, Krupp LB, Enoka RM. Fatigue and fatigability in neurologic illnesses: proposal for a unified taxonomy. Neurology 2013; 80: 409-416.

4 Saketkoo LA, Grewal HK, Yandle G, et al. Fatigue may have an impact on functioning and quality of life equal to that of dyspnea in patients with pulmonary hypertension. Am J Respir Crit Care Med 2013; 187: A3306.

5 Matura LA, McDonough A, Carroll DL. Symptom prevalence, symptom severity, and health-related quality of life among young, middle, and older adults with pulmonary arterial hypertension. Am J Hosp Palliat Care 2016; 33: $214-221$.

6 Rubenfire M, Lippo G, Bodini BD, et al. Evaluating health-related quality of life, work ability, and disability in pulmonary arterial hypertension: an unmet need. Chest 2009; 136: 597-603.

7 Saketkoo LA, Grewal HK, Erbil J, et al. The World Health Organization's (WHO) International Classification of Functioning Health and Disability (ICF): an emerging language for pulmonary hypertension. Am J Respir Crit Care Med 2013; 187: A3302.

8 Lowe B, Grafe K, Ufer C, et al. Anxiety and depression in patients with pulmonary hypertension. Psychosom Med 2004; 66: 831-836.

9 Buffart LM, De Backer IC, Schep G, et al. Fatigue mediates the relationship between physical fitness and quality of life in cancer survivors. J Sci Med Sport 2013; 16: 99-104.

10 Gobbi C, Rocca MA, Riccitelli G, et al. Influence of the topography of brain damage on depression and fatigue in patients with multiple sclerosis. Mult Scler 2014; 20: 192-201.

11 Jones J, McDermott CM, Nowels CT, et al. The experience of fatigue as a distressing symptom of heart failure. Heart Lung 2012; 41: 484-491.

12 Nikolaus S, Bode C, Taal E, et al. Fatigue and factors related to fatigue in rheumatoid arthritis: a systematic review. Arthritis Care Res 2013; 65: 1128-1146.

13 Stocchi F, Abbruzzese G, Ceravolo R, et al. Prevalence of fatigue in Parkinson disease and its clinical correlates. Neurology 2014; 83: 215-220.

14 Smets EM, Garssen B, Bonke B, et al. The Multidimensional Fatigue Inventory (MFI) psychometric qualities of an instrument to assess fatigue. J Psychosom Res 1995; 39: 315-325. 
15 Purcell A, Fleming J, Bennett S, et al. Determining the minimal clinically important difference criteria for the Multidimensional Fatigue Inventory in a radiotherapy population. Support Care Cancer 2010; 18: 307-315.

16 Lin JM, Brimmer DJ, Maloney EM, et al. Further validation of the Multidimensional Fatigue Inventory in a US adult population sample. Popul Health Metr 2009; 7: 18.

17 Bennett JA, Riegel B, Bittner V, et al. Validity and reliability of the NYHA classes for measuring research outcomes in patients with cardiac disease. Heart Lung 2002; 31: 262-270.

18 Smets EM, Garssen B, Cull A, et al. Application of the multidimensional fatigue inventory (MFI-20) in cancer patients receiving radiotherapy. Br J Cancer 1996; 73: 241-245.

19 Rupp I, Boshuizen HC, Jacobi CE, et al. Impact of fatigue on health-related quality of life in rheumatoid arthritis. Arthritis Rheum 2004; 51: 578-585.

20 Galiè N, Barberà JA, Frost AE, et al. Initial use of ambrisentan plus tadalafil in pulmonary arterial hypertension. N Engl J Med 2015; 373: 834-844.

21 van der Lee ML, Garssen B. Mindfulness-based cognitive therapy reduces chronic cancer-related fatigue: a treatment study. Psychooncology 2012; 21: 264-272.

22 Spahn G, Choi KE, Kennemann C, et al. Can a multimodal mind-body program enhance the treatment effects of physical activity in breast cancer survivors with chronic tumor-associated fatigue? A randomized controlled trial. Integr Cancer Ther 2013; 12: 291-300.

23 Simpson R, Booth J, Lawrence $\mathrm{M}$, et al. Mindfulness based interventions in multiple sclerosis - a systematic review. BMC Neurol 2014; 14: 15.

24 Sturm I, Baak J, Storek B, et al. Effect of dance on cancer-related fatigue and quality of life. Support Care Cancer 2014; 22: 2241-2249.

25 Johansson B, Bjuhr H, Rönnbäck L. Mindfulness-based stress reduction (MBSR) improves long-term mental fatigue after stroke or traumatic brain injury. Brain Inj 2012; 26: 1621-1628.

26 Kim YH, Kim HJ, Ahn SD, et al. Effects of meditation on anxiety, depression, fatigue, and quality of life of women undergoing radiation therapy for breast cancer. Complement Ther Med 2013; 21: 379-387.

27 Barton DL, Liu H, Dakhil SR, et al. Wisconsin Ginseng (Panax quinquefolius) to improve cancer-related fatigue: a randomized, double-blind trial, N07C2. J Natl Cancer Inst 2013; 105: 1230-1238.

28 Cella D, Lai JS, Jensen SE, et al. PROMIS fatigue item bank had clinical validity across diverse chronic conditions. J Clin Epidemiol 2016; 73: 128-134.

29 Matura LA, McDonough A, Hanlon AL, et al. Sleep disturbance, symptoms, psychological distress, and health-related quality of life in pulmonary arterial hypertension. Eur J Cardiovasc Nurs 2015; 14: 423-430.

30 Minnock P, Kirwan J, Bresnihan B. Fatigue is a reliable, sensitive and unique outcome measure in rheumatoid arthritis. Rheumatology 2009; 48: 1533-1536.

31 McKenna SP, Doughty N, Meads DM, et al. The Cambridge Pulmonary Hypertension Outcome Review (CAMPHOR): a measure of health-related quality of life and quality of life for patients with pulmonary hypertension. Qual Life Res 2006; 15: 103-115.

32 Matura LA, McDonough A, Carroll DL. Symptom interference severity and health-related quality of life in pulmonary arterial hypertension. J Pain Symptom Manage 2016; 51: 25-32. 